\title{
STRATEGI IMPRESSION MANAGEMENT PINILIH MOJANG 2014-2015 DALAM MEREPRESENTASIKAN KOTA BANDUNG
}

\author{
Muhamad Arfi Annafidin ${ }^{1}$, Trie Damayanti' ${ }^{2}$, dan Kokom Komariah ${ }^{3}$ \\ ${ }^{1,2,3}$ Universitas Padjadjaran
}

\begin{abstract}
ABSTRAK
Pasanggiri Mojang Jajaka merupakan agenda tahunan pemerintah daerah di Jawa Barat, termasuk Pemerintah Kota Bandung. Kegiatan ini merupakan salah satu ajang untuk lebih mengenalkan karakter budaya tradisional kepada para nonoman (generasi muda). Dengan lebih mengenal budaya sendiri maka diharapkan di kalangan generasi muda akan tumbuh kebanggaan dan kecintaan terhadap budaya sendiri dan memiliki filter terhadap masuknya budaya luar. Sebagai Pinilih Mojang dan Jajaka Kota Bandung, Pinilih harus memenuhi Kriteria Mojang dan Jajaka yang telah ditentukan oleh paguyuban seperti anggun, beribawa, bersih, berwawasan luas, pintar public speaking, dan lancar bahasa Sunda. Tujuan dari Penelitian ini untuk mengetahui strategi impression management Pinilih Mojang 2014-2015 yang meliputi kesan yang dicari, menunjukkan perilaku, dan menyiapkan risiko dari presentasi diri dalam merepresentasikan Kota Bandung. Metode yang digunakan pada penelitian ini adalah metode eksploratif dengan data-data kualitatif. Teknik pengumpulan data yang digunakan adalah observasi, wawancara dan studi kepustakaan. Teknik pengumpulan Key Informant dengan cara purposive sampling. Teknik analisis data menggunakan tiga analisis yaitu domain, taksonomi dan komponensial. Teknik validitas data menggunakan triangulasi sumber. Hasil penelitian menunjukkan bahwa strategi impression management yang dilakukan oleh Pinilih Mojang 2014-2015 Akasha dan Nabila menampilkan kesan yang dicari dalam Mojang Kota Bandung, lalu Akasha dan Nabila menunjukkan perilaku yang harus dilakukan oleh Mojang Kota Bandung saat bertugas, dan Akasha dan Nabila menerima risiko apa yang terjadi saat menjadi Mojang dan menyiapkan risiko yang akan terjadi saat jadi mojang. Saran yang diberikan melalui penelitian ini adalah tidak semua kompetensi yang dicari dalam Mojang Kota Bandung terdapat pada Akasha dan Nabila seperti anggun dan feminin, namun Akasha dan Nabila harus memperbaiki kompetensi yang tidak ada dalam diri mereka, dan perilaku harus tetap dijaga meskipun tidak saat bertugas sebagai Mojang Kota Bandung.
\end{abstract}

Kata-kata Kunci: Impression management, mojang, representasi, presentasi diri, kota Bandung

\section{IMPRESSION MANAGEMENT STRATEGY OF MOJANG PINILIH 2014-2015 IN REPRESENTING BANDUNG CITY}

\begin{abstract}
Pasanggiri Mojang Jajaka is an annual agenda of local governments in West Java, including the Government of Bandung. This activity is one of the event to introduce more traditional cultural character to the nonoman (young generation). By getting to know their own culture it is hoped that among the younger generation will grow pride and love for their own culture and have a filter on the influx of foreign culture. As Pinilih Mojang and Jajaka Bandung, Pinilih must meet the criteria Mojang and Jajaka that has been determined by the community such as graceful, dignified, clean, broad-minded, smart public speaking, and fluent Sundanese language. The purpose of this study was to determine the impression management strategy Pinilih Mojang 2014-2015 which includes the impression sought, the behaviors, and the self-presentation to prepare the risk in representing the city of Bandung. The method used in this study is exploratory with qualitative data. The data collection techniques used were observation, interview, and literature study. The Key Informant we choose with purposive technique. The analysis data technique used three domains namely analysis, taxonomy and componential, with sources triangulation as a validity data technique. The result showed that The impression management strategy conducted by Pinilih Mojang 2014-2015, Akasha and Nabila show the impression in sought as Mojang Bandung; Akasha and Nabuka also shows their behavior that must be carried out by Mojang Bandung while on duty; They also accept what risk which occurred when they became Mojang and prepare the risk that will occurs when they were a Mojang. Advice given through this study that not all the competencies sought in Mojang Bandung like graceful and feminine appears in Akasha and Nabila, but They should improve their competencies which are not their personality, and thy have to maintained their behavior although not while working as Mojang of Bandung city.
\end{abstract}

Keywords: Impression management, mojang, representation, self presentation, Bandung city

Korespondensi: Muhamad Arfi Annafidin, S.I.Kom. Program Studi Hubungan Masyarakat, Fakultas Ilmu Komunikasi, Universitas Padjadjaran, Jl. Raya Bandung-Sumedang Km 21, Jatinangor 45363. Email: arfiannafidin@gmail.com 


\section{PENDAHULUAN}

Pasanggiri Mojang Jajaka merupakan agenda tahunan pemerintah daerah di Jawa Barat, termasuk Pemerintah Kota Bandung. Kegiatan ini merupakan salah satu ajang untuk lebih mengenalkan karakter budaya tradisional kepada para nonoman (generasi muda). Dengan lebih mengenal budaya sendiri maka diharapkan di kalangan generasi muda akan tumbuh kebanggaan dan kecintaan terhadap budaya sendiri dan memiliki filter terhadap masuknya budaya luar (Wisata Bandung, 2015). Sebagai Pinilih Mojang dan Jajaka Kota Bandung, Pinilih harus memenuhi Kriteria Mojang dan Jajaka yang telah ditentukan oleh paguyuban seperti anggun, beribawa, bersih, berwawasan luas, pintar public speaking, dan lancar bahasa Sunda.

Pada kenyataannya Pinilih mojang Bandung ini memiliki sifat yang berbeda dalam keseharian mereka sebagai Mojang, baik Nabila maupun Akasha. Nabila pada kehidupan kesehariannya saat tidak bertugas sebagai mojang adalah sosok wanita yang tomboy, cuek dalam berpakaian, bahkan saat berkumpul dengan teman-temannya dia terlihat lepas dan menunjukkan dirinya yang sebenarnya. Tidak terlihat sesosok mojang Bandung pada diri Nabila saat dia sedang bertugas sebagai Mojang Bandung. Cuek dan tomboy bertolak belakang pada diri mojang yang seharusnya anggun dan berwibawa.
Sama halnya dengan profesi Mojang Jajaka tidak semua peserta Mojang dan Jajaka sejalan dengan kepribadian mereka sehari-hari. Ini yang dialami oleh Nabila dan Akasha, bertolak belakang dengan sikap yang seharusnya ada didalam Mojang. Namun, mau tidak mau mereka harus melakukan profesinya sebagai Mojang dengan baik untuk mendapatkan kesan yang baik dimata khayalak.

Berdasarkankonteks penelitian diatas, maka yang menjadi fokus kajian penelitian ini adalah: "Bagaimana Strategi Impression Management Pinilih Mojang dalam merepresentasikan Kota Bandung?". Sedangkan tujuan dilakukannya penelitian ini yaitu: 1 . Untuk mengetahui Pinilih Mojang menampilkan kesan yang dicari dalam merepresentasikan Kota Bandung, 2. Untuk mengetahui Pinilih Mojang menunjukkan perilaku dalam merepresentasikan Kota Bandung, dan 3. Untuk mengetahui Pinilih Mojang menyiapkan risiko dari presentasi diri dalam merepresentasikan Kota Bandung.

Kegunaan teoritis dari hasil penelitian ini diharapkan dapat memberikan masukan berupa pengetahuan bagi kajian Ilmu Hubungan Masyarakat yang bermanfaat bagi perkembangan Ilmu Hubungan Masyarakat khususnya dalam kajian penelitian kualitatif serta menambah pengetahuan atau referensi untuk bahan penelitian selanjutnya. Sedangkan kegunaan praktisnya adalah sebagai tambahan pengetahuan bagi para praktisi dan pemerhati Mojang dan Jajaka Kota Bandung dalam

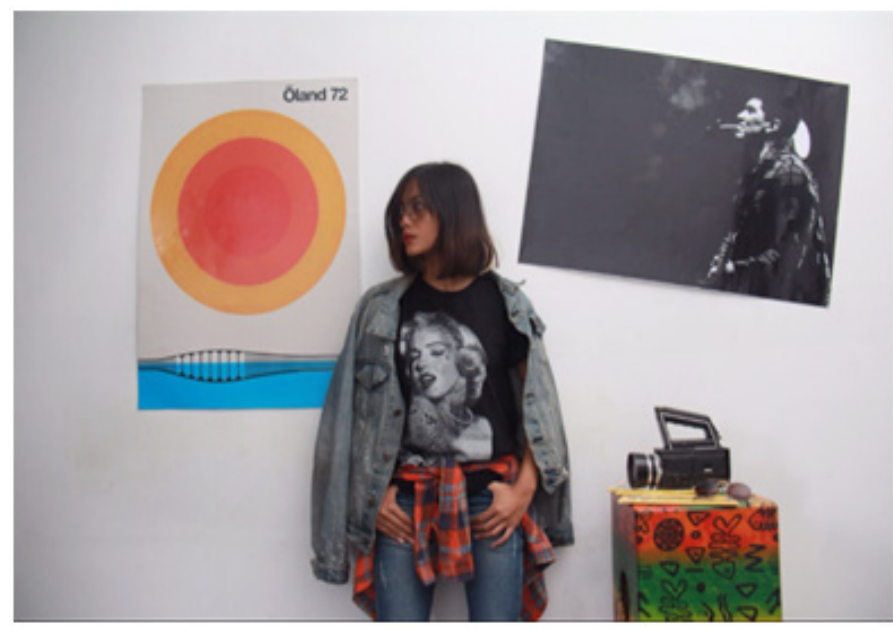

Sumber: Data Pribadi milik Akasha

Gambar 1 Akasha saat memakai pakaian sehari-hari 
mengetahui strategi impression management Mojang dan Jajaka, sehingga kegiatan Mojang dan Jajaka Kota Bandung yang akan dilakukan selanjutnya dapat berjalan lebih baik dan menciptakan citra yang positif dari para Mojang dan Jajaka, serta mampu mengangkat citra Kepariwisataan Kota Bandung yang positif di mata Nasional maupun Internasional.

\section{METODE PENELITIAN}

Peneliti menggunakan metode penelitian kualitatif, yang mana pendekatan penelitian kualitatif merupakan metode yang berdasarkan pada mutu atau kualitas tujuan penelitian tersebut. Artinya data yang dikumpulkan bukan berupa angka-angka melainkan data tersebut berdasarkan dari wawancara, catatan lapangan, dokumen pribadi, catatan memo, dan dokumen resmi lainnya.

Penelitian ini menghasilkan data deskriptif berupa ucapan atau tulisan perilaku di balik fenomena secara mendalam dari orang-orang yang diamati, dalam hal ini yaitu Pinilih Mojang Penggunaan pendektan kualitatif dalam penelitian ini adalah mencocokan antara realita empirik dengan teori yang berlaku.
Sesuai dengan paradigma yang digunakan oleh penulis dalam penelitian ini adalah paradigma post positivisme. Post-positivis mempertahankan filsafat deterministik bahwa sebab-sebab (faktor-faktor kausal) sangat mungkin menentukan akibat atau hasil akhir. Untuk itulah, masalah-masalah yang dikaji oleh kaum post-positivis mencerminkan adanya kebutuhan untuk mengidentifikasi faktor-faktor penyebab yang mempengaruhi hasil akhir (Cresswel, 2009).

Penelitian ini mencari tahu faktor-faktor pada impression management Pinilih Mojang Kota Bandung tahun 2014 dan 2015 dalam merepresentasikan Kota Bandung. Penelitian ini mencari tahu proses apa yang terjadi dalam melaksanakan tugas Mojang Kota Bandung bagi Pinilih Mojang 2014 dan 2015 meskipun sikap mereka tidak sesuai dengan sikap Mojang Kota Bandung dalam kesehariannya.

Strategi impression management Pinilih Mojang Bandung dalam Merepresentasikan Kota Bandung adalah jenis studi eksploratif. Penelitian eksploratif memiliki kedudukan cukup penting dalam ilmu sosial, khususnya untuk menghasilkan temuan-temuan baru. Pendekatan ini selalu menghasilkan berbagai

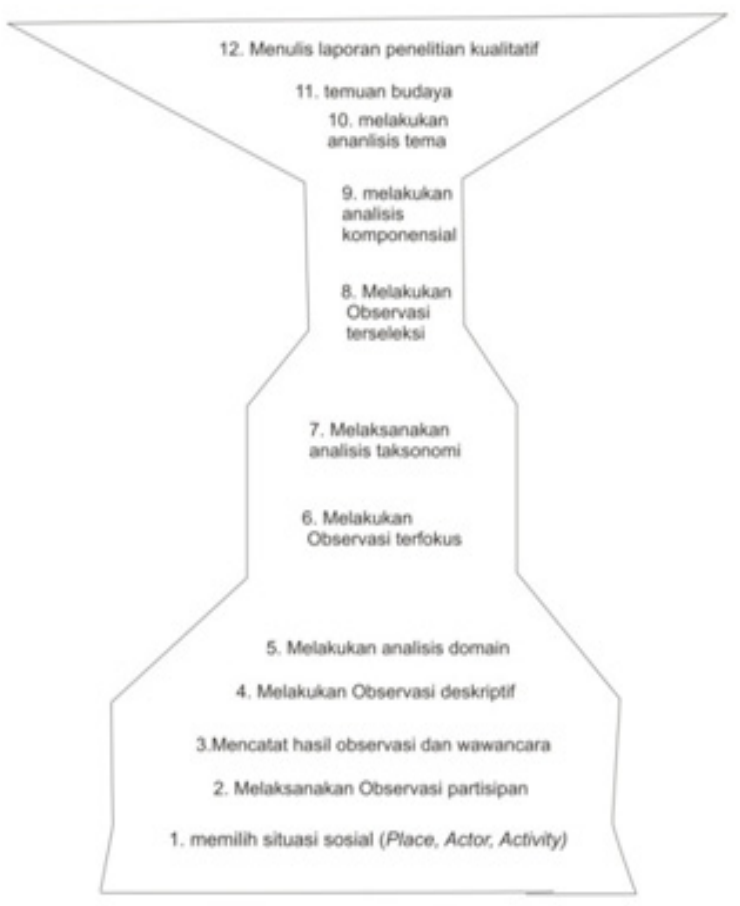

Sumber: Sugiyono, 2010

Gambar 2 Tahapan Penelitian kualitatif 
gagasan mengenai topik-topik baru penelitian. Kelemahan utama penelitian eksploratif adalah jarang memberikan jawaban yang memuaskan terhadap pertanyaan penelitian, walaupun pendekatan eksploratif memberikan petunjuk jawaban dan saran mengenai metode riset yang dapat digunakan untuk memberikan jawaban yang lebih pasti (Morissan, 2012: 36).

Dalam penelitian ini peneliti memilih informan yang menjadi subjek penelitian ini dipilih berdasarkan teknik purposive sampling (sampel bertujuan). Purposive sampling adalah pengambilan sampel sumber data dengan pertimbangan tertentu. Pertimbangan tertentu ini, misalnya orang tersebut yang dianggap paling tahu tentang apa yang kita harapkan, atau mungkin dia sebagai penguasa sehingga akan memudahkan peneliti menjelajahi objek/situasi sosial yang diteliti. (Sugiyono, 2010: 215). Key informant dari penelitian ini Pinilih Mojang Kota Bandung 2014 dan 2015 yaitu Akasha dan Nabila

Dalam penelitian kualitatif, pengumpulan data dapat dilakukan pada natural setting (kondisi yang alamiah), sumber data primer, dan teknik pengumpulan data lebih banyak pada observasi, wawancara dan dokumentasi menurut Catherine Marshall, Gretchenn B, Rossman (Sugiyono, 2010: 225). Apabila dilihat dari sumber datanya, maka pengumpulan datanya menggunakan sumber primer dan sumber sekunder, sebagai berikut: data primer adalah data yang diperoleh secara langsung dari sumbernya, diamati, dan dicatat dari wawancara dan observasi.

Teknik analisis data yang digunakan dalam penelitian ini berdasarkan pada teknik analisis Spradley (dalam Sugiyono, 2010) membagi analisis data dalam penelitian kualitatif berdasarkan tahapan dalam penelitian kualitatif. Proses penelitian kualitatif setelah memasuki lapangan, dimulai dengan menetapkan seseorang informan kunci "Key Informant" yang merupakan informan yang berwibawa dan dipercaya mampu "membukakan pintu" kepada peneliti untuk memasuki objek penelitian. Jadi proses penelitian berangkat dari yang luas, kemudian memfokus, dan meluas lagi. Terdapat tahapan analisis data yang dilakukan dalam penelitian kualitatif, yaitu analisis domain, taksonomi, komponensial, analisis tema.

Penelitian ini menggunakan triangulasi sumber sebagai teknik validitas data, dengan mewawancara Kang Fajar sebagai Ketua Paguyuban Mojang Jajaka Kota Bandung.

\section{HASIL DAN PEMBAHASAN}

Pasanggiri Mojang Jajaka merupakan agenda tahunan pemerintah daerah di Jawa Barat, termasuk Pemerintah Kota Bandung. Kegiatan ini merupakan salah satu ajang untuk lebih mengenalkan karakter budaya tradisional kepada para nonoman (generasi muda). Dengan lebih mengenal budaya sendiri maka diharapkan di kalangan generasi muda akan tumbuh kebanggaan dan kecintaan terhadap budaya sendiri dan memiliki filter terhadap serangan budaya luar (Wisata Bandung, 2015).

Pasanggiri Mojang dan Jajaka memiliki maksud dan tujuan yaitu Fokus utama dari kegiatan ini ialah untuk mendukung proses pembentukan suatu regenerasi budaya yang ideal, dengan menghasilkan sosok generasi muda yang memiliki jati diri sunda, yang berciri: Pengkuh Agamana (melaksanakan IMTAQ sesuai ajaran religinya), Luhung Elmuna (berdaya saing), Jembar Budayana (Tidak gagap budaya dan berjati diri sunda), Rancage Gawena (berprestasi dan berpartisipasi aktif dalam berbagai bidang). Kualitas ini akan ditumbuhkan untuk menghasilkan sosok generasi muda yang dapat merepresentasikan Kota Bandung dalam seluruh aspeknya pada masyarakat nasional dan internasional (Mojang Jajaka, 2013).

Impression management atau pengelolaan kesan ditemukan dan dikembangkan oleh Erving Goffman pada tahun 1959. Pengelolaan kesan juga secara umum dapat didefinisikan sebagai sebuah teknik presentasi diri yang didasarkan pada tindakan mengontrol persepsi orang lain dengan cepat dengan mengungkapkan aspek yang dapat menguntungkan diri sendiri atau tim.

Pengelolaan kesan adalah proses di mana orang mencoba mempengaruhi persepsi dari citra mereka. Mereka melakukannya 
dengan mengendalikan dan mengelola informasi disajikan di media sosial. Penyajian identitas adalah kunci keberhasilan atau kegagalan misalnya dalam kehidupan bisnis (Paliszkiewicz \& Madra-sawicka, 2011).

Menurut Goffman (1959), impression management erat kaitannya dengan sebuah permainan drama, dimana aktor pelakunya dibentuk oleh lingkungan dan target penontonnya. Tujuannya tak lain ialah untuk memberikan penonton sebuah kesan yang konsisten yang dilandasi tujuan yang diinginkan oleh aktor itu sendiri. Lima strategi presentasi diri yang diungkapkan oleh Jones (1990) yaitu (1). Ingratiasi (ingratiation). Ingratiasi adalah usaha yang disengaja untuk menciptakan kesan baik. Banyak orang berupaya melakukan ini. Dorongan berbuat baik karena ingin memperoleh pujian. Misalnya menyumbang jumlah besar pada orang susah, membantu kaum miskin, sampai memberikan uang pada pengemis hanya untuk dianggap dermawan. (2). Promosi diri (self promotion). Ketika tujuan seseorang adalah supaya dilihat nampak kompeten atau ahli pada tugas tertentu, strategi promosi diri biasanya digunakan. Orang yang menggunakan strategi ini akan menggambarkan kekuatankekuatan dan berusaha untuk memberi kesan dengan prestasi mereka. Melebih-lebihkan tentang kemampuan diri dapat berisiko mereka dianggap sombong, dan tidak dapat dipercaya. Menyadari masalah ini, cara yang digunakan adalah tidak langsung sehingga memungkinkan orang lain sampai pada kesimpulan bahwa dia kompeten. Jadi strategi ini adalah tindakan yang dirancang untuk membuat seseorang tampak lebih kompeten. Biasanya para pencari kerja berusaha melakukan promosi diri pada saat wawancara kerja. Mereka berupaya menunjukkan diri mampu dan layak diterima kerja. (3) Intimidasi (intimidation). Intimidasi adalah strategi presentasi diri dimana orang mengkomunikasikan suatu kemampuan dan kecenderungan untuk menyebabkan orang lain menghasilkan sesuatu yang negatif. Misalnya pamer kekayaan untuk membuat seseorang merasa rendah diri. (4) Eksemplifikasi (exemplification). Orang yang menggunakan strategi ini berusaha memproyeksikan penghargaannya pada kejujuran dan moralitas. Biasanya mereka mempresentasikan dirinya sebagai orang yang jujur, disiplin dan baik hati atau dermawan. Kadang-kadang penampilan yang ditunjukkan ini memang keadaan yang sebenarnya, namun yang sering pengguna strategi ini berusaha memanipulasi dan tidak tulus hati dalam melakukannya. Untuk

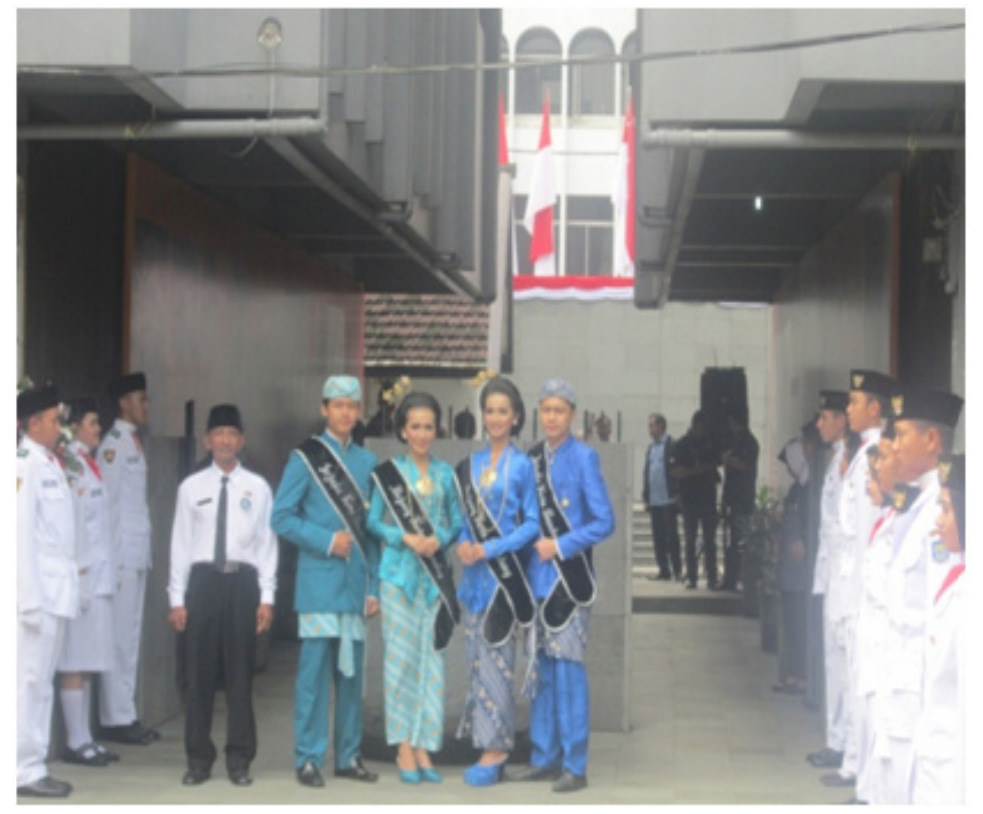

Sumber: Data Pribadi

Gambar 4 Nabila Saat Bertugas di Monumen Penjara Banceuy 
melakukan strategi-strategi yang tersebut di atas. Biasanya yang dilakukan adalah melakukan kritik pada diri sendiri, dan (5) Suplikasi (supplication). Permohonan (supplication). Strategi ini dengan cara memperlihatkan kelemahan atau ketergantungan untuk mendapatkan pertolongan atau simpati. Ini merupakan alternatif strategi yang terakhir, jika orang tidak memiliki sumber-sumber yang dapat digunakan.

Berdasarkan hasil penelitian yang diamati kepada Pinilih Mojang Kota Bandung 2014 dan 2015, Pinilih Mojang 2014-2015 menampilkan kesan yang dicari dalam merepresentasikan Kota Bandung. Pinilih Mojang Kota Bandung 2014 dan 2015 Akasha dan Nabila menampilkan kesan yang dicari dalam Mojang Kota Bandung yaitu kompetensi. Kompetensi Mojang Kota Bandung yaitu, catwalk, public speaking, cerdas, anggun, wibawa, tahan demam panggung, feminin, komunikatif dan diplomatis. Akasha dan Nabila menunjukkan kompetensi Mojang Kota Bandung saat mereka bertugas meskipun ada beberapa kompetensi yang mereka tidak kuasai seperti anggun dan feminin namum mereka dapat mengatasi hal tersebut sehingga tidak terlihat kekurangan mereka saat bertugas.

Dalam konteks ini Akasha dan Nabila adalah aktor yang memerankan Mojang kota Bandung. Aksaha dan Nabila harus mampu menunjukkan kompetensi yang dimiliki oleh Mojang Kota Bandung agar dapat merepresentasikan Mojang Kota Bandung. Dalam konteks ini peneliti membagikan kompetensi yang ada dalam diri Mojang menjadi dua yaitu Konsep diri dan Keterampilan.

Konsep diri adalah sikap, nilai-nilai, atau citra diri seseorang. Percaya diri merupakan keyakinan orang bahwa mereka dapat efektif dalam hampir setiap situasi adalah bagian dari konsep diri orang (Spencer dan Spencer dalam Sedarmayanti, 2011: 226). Dalam kompetensi ini yang termasuk konsep diri yaitu tahan demam panggung, anggun, feminin, wibawa, dan komunikatif. Sedangkan keterampilan adalah kemampuan mengerjakan tugas fisik atau mental tertentu (Zwell dalam Sedarmayanti, 2011: 54). Kompetensi mental atau keterampilan kognitif termasuk berpikir
Tabel 1 Hasil Self Monitor Akasha

\begin{tabular}{|c|c|c|c|}
\hline 1. & $\mathrm{~T}$ & $\mathrm{~F}$ & $\begin{array}{l}\text { Saya tekun dalam mempelajari } \\
\text { sesuatu. }\end{array}$ \\
\hline 2. & $\mathrm{~T}$ & $\mathrm{~F}$ & Saya adalah orang yang anggun. \\
\hline 3. & $\mathrm{~T}$ & $\mathrm{~F}$ & $\begin{array}{l}\text { saya mudah grogi saat tampil } \\
\text { depan orang. }\end{array}$ \\
\hline 4. & $\mathrm{~T}$ & $\mathrm{~F}$ & Saya dapat melakukan Catwalk. \\
\hline 5. & $\mathrm{~T}$ & $\mathrm{~F}$ & $\begin{array}{l}\text { Saya memilih kata yang tepat } \\
\text { sebelum mengeluarkan pendapat. }\end{array}$ \\
\hline 6. & $\mathrm{~T}$ & $\mathrm{~F}$ & $\begin{array}{l}\text { Saya bisa membuat pidato } \\
\text { dadakan bahkan pada topik } \\
\text { tentang yang saya hampir tidak } \\
\text { tahu sama sekali. }\end{array}$ \\
\hline 7. & $\mathrm{~T}$ & $\mathrm{~F}$ & $\begin{array}{l}\text { Saya mempunyai daya tarik untuk } \\
\text { membuat orang lain segan. }\end{array}$ \\
\hline 8. & $\mathrm{~T}$ & $\mathrm{~F}$ & $\begin{array}{l}\text { Apa yang saya ucapkan dapat } \\
\text { dimengerti oleh orang lain. }\end{array}$ \\
\hline 9. & $\mathrm{~T}$ & $\mathrm{~F}$ & Saya lebih suka memakai sneaker. \\
\hline
\end{tabular}

Tabel 2 Hasil Self Monitor Nabila

\begin{tabular}{llll}
\hline 1. & T & F & $\begin{array}{l}\text { Saya tekun dalam mempelajari } \\
\text { sesuatu. }\end{array}$ \\
\hline 2. & T & F & Saya adalah orang yang anggun. \\
\hline 3. & T & F & $\begin{array}{l}\text { saya mudah grogi saat tampil } \\
\text { depan orang. }\end{array}$ \\
\hline 4. & T & F & Saya dapat melakukan Catwalk. \\
\hline 5. & T & F & $\begin{array}{l}\text { Saya memilih kata yang tepat } \\
\text { sebelum mengeluarkan pendapat. }\end{array}$ \\
\hline 6. & T & F & $\begin{array}{l}\text { Saya bisa membuat pidato } \\
\text { dadakan bahkan pada topik } \\
\text { tentang yang saya hampir tidak } \\
\text { tahu sama sekali. }\end{array}$ \\
\hline 7. & T & F & $\begin{array}{l}\text { Saya mempunyai daya tarik untuk } \\
\text { membuat orang lain segan. }\end{array}$ \\
\hline 8. & T & F & $\begin{array}{l}\text { Apa yang saya ucapkan dapat } \\
\text { dimengerti oleh orang lain. }\end{array}$ \\
\hline
\end{tabular}




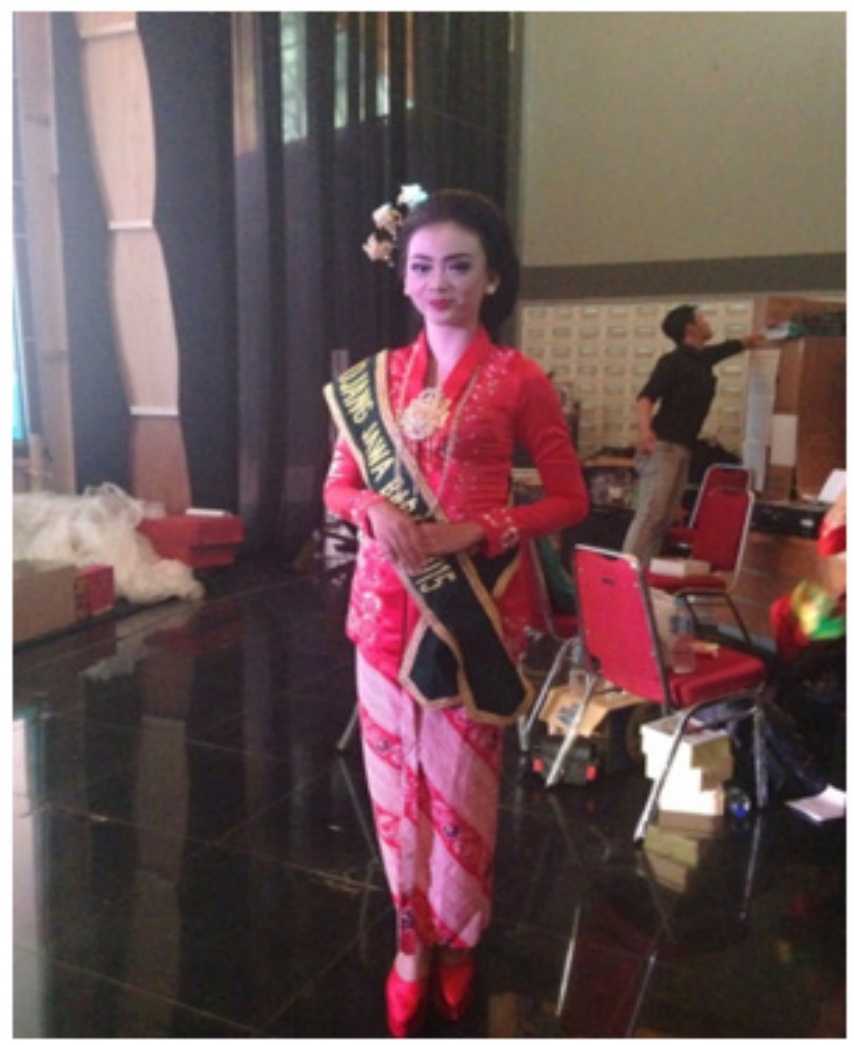

Sumber: Data Pribadi

Gambar 5 Akasha Saat di Belakang Panggung

analitis dan konseptual saat Pinilih Mojang Kota Bandung bertugas, kompetensi ini meliputi catwalk, public speaking yang baik, cerdas dan diplomatis.

The self-concept seems like a very private phenomenon. After all, people's thoughts about themselves are hidden and are often

Tabel 3 Hasil Kesadaran Diri Akasha

\begin{tabular}{llllll}
\hline 1. Memberikan senyuman & 1 & 2 & 3 & 4
\end{tabular} kepada orang lain.

\begin{tabular}{llllll}
\hline 2. & Ramah kepada masyarakat & 1 & 2 & 3 & 4 \\
\hline 3. & Sopan santun & 1 & 2 & 3 & 4
\end{tabular}

Tabel 4 Hasil Kesadaran Diri Akasha

\begin{tabular}{|c|c|c|c|c|}
\hline $\begin{array}{l}\text { 1. Memberikan senyuman } \\
\text { kepada orang lain. }\end{array}$ & & & & \\
\hline 2. Ramah kepada masyarakat & 1 & & & \\
\hline 3. Sopan santun & 1 & 2 & & \\
\hline
\end{tabular}

highly personal. Yet the self-concept is also very much a social phenomenon. It has social roots (e.g., reflected appraisals, social comparison), it includes social identities and roles, and it guides our perception of others and our behavior in social settings (Eliot \& Prufrock, 2013).

Pada konsep self promotion, kesan yang dicari yaitu kompetensi. Kompetensi yang ditujukkan oleh Akasha dan Nabila harus sesuai dengan kompetensi yang dimiliki oleh Mojang Kota Bandung. Maka dari itu penelitian ini menggunakan self monitor untuk mengetahui sejauh mana Akasha dan Nabila mengontrol diri mereka untuk menunjukkan kompetensi yang seharusnya dimiliki oleh seorang Mojang Kota Bandung. Terry mengemukakan bahwa promosi dapat dilakukan menggunakan media:

"There are also concerns by media experts that promotions combined with advertising have a direct effect of diminishing the quantity of news available on these platforms thereby reducing the public's ability to be informed about issues of the day" (Terry, 2013). 
Self monitor yang dilakukan oleh Pinilih Mojang Kota Bandung 2014 dan 2015 yaitu Akasha dan Nabila memiliki monitor diri yang tinggi. Self monitor mereka dilakukan karena untuk menunjukkan kompetensi yang dimiliki oleh Mojang Kota Bandung. Akasha dan Nabila memiliki nilai 7 dari 9. Nilai 7 menunjukkan self monitor yang tinggi artinya Akasha dan Nabila memiliki tujuan menjadi orang yang benar dan mengetahui apa yang harus dilakukan dan bagaimana harus bersikap sesuai dengan situasi tertentu.

Berdasarkan hasil pengamatan peneliti tentang perilaku yang ditunjukkan oleh Akasha dan Nabila menunjukkan perilaku dalam merepresentasikan Kota Bandung. Perilaku yang ditunjukkan saat Akasha dan Nabila bertugas harus menunjukkan perilaku mojang Bandung. Ada beberapa perilaku mojang bandung seperti murah senyum, someah hade kasemah atau ramah, dan sopan santun.

Pertama perilaku yang ditunjukkan oleh Akasha saat bertugas di acara HIPMI saat di depan panggung maupun saat mengelilingi tenant-tenant yang ada di luar. Dia memberikan senyuman kepada peserta HIPMI maupun ke pengunjung yang datang ke tenant tersebut. Ramah pun terlihat jelas selain dengan murah senyum saat bertugas Akasha pun memberikan sapaan dengan sedikit menundukan kepala dan membungkukan badannya saat ada orang yang menyapa dirinya. Murah senyum dan ramah terlihat dengan perilaku yang ditunjukkan Akasha. Selain itu juga sopan santun harus ditunjukkan oleh Akasha saat bertugas sebagai mojang. Sopan santun terlihat dalam perilaku yang ditunjukan Akasha. Gerakan yang anggun dan sopan santun terlihat saat Akasha memberikan plakat kepada pembicara HIPMI.

Pada peringatan hari Pancasila ini, Nabila bertugas di hadapan masyarakat kota Bandung. Bertempat di Monument Penjara Banceuy untuk menyambut datangnya Presiden Indonesia. Bertugas di depan banyak orang khususnya di hadapan masyarakat kota Bandung harus dapat memberikan kesan di mata masyarakat bahwa dia adalah seorang mojang Bandung, dan juga harus menunjukkan perilaku yang menunjukkan bahwa dia adalah seorang pinilih mojang Bandung. Memberikan senyuman kepada masyarakat saat berdiri di hadapan masyarakat. Banyak masyarakat yang meneriaki dan memotret dirinya. Selain memberikan senyuman kepada masyarakat saat berdiri di depan untuk menyambut Presiden Indonesia, Nabila menunjukkan perilaku mojang dalam dirinya yaitu ramah. Meskipun terlihat berusaha untuk memberikan senyuman kepada masyarakat, Nabila menunjukkan keramahan. Keramahan yang ditunjukkan yaitu memberikan salam dengan cara menundukkan kepala, sedikit menekukan lututnya dan memberikan sikap salam. Terlihat sangat sopan dalam acara ini. Dia berdirimenunggu datangnya Presiden namun tidak melupakan masyarakat yang ada di sekitarnya. Terus memberikan rasa hormat kepada masyarakat yang hadir dengan cara berdiri ala Mojang Bandung.

Perilaku yang ditunjukkan harus disadari dengan kesadaran diri saat berada dalam masyarakat. Kesadaran diri saat di publik digunakan untuk menilai sejauh mana orang fokus pada masyarakat. Kesadaran diri di depan publik yang ditunjukkan Akasha dan Nabila mendapatkan nilai 10 dan 11 dari total 12. Akasha dan Nabila mendapatkan nilai tinggi, artinya mereka memiliki kesadaran diri depan publik yang tinggi. Mereka dapat mengartikan diri mereka sebagai objek sosial dan mereka memikirkan penampilan mereka di depan publik. Akasha dan Nabila menunjukkan perilaku yang dimiliki oleh seorang Mojang Kota Bandung saat mereka bertugas di depan masyarakat. Mereka memperhatikan perilakuperilaku Mojang seperti murah senyum, someah hade kasemah atau ramah, dan sopan santun saat mereka bertugas sebagai Mojang untuk merepresentasikan Mojang Kota Bandung.

Perilaku seseorang dipengaruhi oleh simbol yang dikeluarkan orang lain, demikian pula perilaku orang lain tersebut. Melalui pemberian isyarat berupa simbol, kita mengutarakan perasaan, pikiran, maksud, dan sebaliknya dengan cara membaca simbol yang ditampilkan orang lain, kita menangkap pikiran dan perasaan orang lain tersebut (Mustafa, 2011).

Hasil penelitian selanjutnya yaitu Pinilih Mojang mempersiapkan risiko dari presentasi 
diri dalam merepresentasikan Kota Bandung. Menyiapkan risiko dari penugasannya sebagai Mojang Bandung Akasha harus bisa jaga diri. Karena dia membawa satu figure Mojang Kota Bandung dalam dirinya yang sudah memiliki standar tersendiri bagi Mojang Bandung dan dia harus bisa memenuhi itu. Lanjutnya, Akasha menjelaskan bahwa menjadi mojang benarbenar harus bisa menjaga diri meskipun dirinya tidak sejalan dengan figure mojang. Namun, dia harus tetap bisa membawakan figure mojang dalam dirinya. Berbeda dengan Nabila yang merupakan Pinilih Mojang Kota Bandung 2015.

Nabila merasa persiapan yang harus dilakukannya yaitu memperbaiki diri, karena dia merasa saat jadi mojang menjadi perhatian masyarakat. Dan dia merasa perbaikan diri pun harus dilakukan dalam kesehariannya karena menjadi perhatian masyarakat setiap saat. tidak saat penugasan saja. Nabila menekankan memperbaiki diri yaitu dengan cara merubah penampilannya. Nabila yang terlihat tomboy dan cuek harus bisa merubah diri dengan ke arah yang lebih bisa menunjukkan dirinya adalah seoarang Mojang Kota Bandung.

Akasha menilai untuk persiapan dalam manner merasa biasa. Akasha merasa dirinya dapat mengetahui situasi sehingga dia paham harus berbuat seperti apa. Namun, awal-awal menjadi mojang Akasha merasa kaget dengan manner mojang Bandung tetapi dia sebisa mungkin harus dapat menyamai manner yang ada di Mojang Bandung. Sama hal dengan Nabila yang merasa tidak menjadi bebas dengan manner yang harus dilakukannya. Nabila melanjutkan bahwa manner yang terdapat di dalam Mojang tidak membuat dirinya menjadi beban, Nabila merasa dengan adanya manner Nabila merasa dirinya menjadi lebih baik daripada diri yang sebelumnya.

Risiko lain dari presentasi diri yaitu merasa angkuh. Namun Nabila tidak merasa dirinya angkuh atau tidak merasa apa-apa. Berbeda dengan Akasha, Akasha merasa angkuh karena dirinya sebagai pinilih Mojang Bandung. Tetapi Akasha menjadikan angkuhan ini sebagai motivasi bagi dirinya untuk menghadapi pesaing-pesaing bukan untuk menjadi kesombongan sendiri.

\section{SIMPULAN}

Berdasarkan hasil penelitian yang telah dikemukakan, dapat ditarik kesimpulan atas penelitian "Strategi Impression Management Pinilih Mojang Kota Bandung" sebagai berikut: Pinilih Mojang 2014- 2015 Akasha dan Nabila menampilkan kesan yang dicari dalam merepresentasikan Mojang Bandung. kesan yang dicari yaitu Kompetensi. Kompetensi Mojang Kota Bandung terdiri dari catwalk, public speaking, cerdas, anggun, wibawa, tahan demam panggung, feminin, komunikatif dan diplomatis. Akasha dan Nabila menunjukkan kompetensi Mojang Kota Bandung saat bertugas. Hasil self monitoring, Akasha dan Nabila memiliki hasil self monitoring 7 dari 9 artinya mereka memiliki self monitor yang tinggi. Self monitor yang tinggi artinya Akasha dan Nabila memiliki tujuan menjadi orang yang benar dan mengetahui apa yang harus dilakukan dan bagaimana harus bersikap sesuai dengan situasi tertentu. Self monitor mereka dilakukan untuk menunjukkan kompetensi yang dimiliki oleh Mojang Kota Bandung.

$$
\text { Pinilih Mojang 2014-2015 Akasha }
$$
dan Nabila menunjukkan perilaku dalam merepresentasikan Mojang Bandung, yaitu murah senyum, someah hade kasemah atau ramah, dan Sopan santun saat bertugas. Kesadaran diri di depan publik yang ditunjukkan Akasha dan Nabila mendapatkan nilai 10 dan 11 dari total 12. Akasha dan Nabila mendapatkan nilai tinggi, artinya mereka memiliki kesadaran diri depan publik yang tinggi. Mereka dapat mengartikan diri mereka sebagai objek sosial dan mereka memikirkan penampilan mereka di depan publik.

Pinilih Mojang 2014-2015 Akasha dan Nabila menyiapkan risiko dari presentasi diri dalam merepresentasikan Mojang Bandung. Risiko yang dialami dalam menjabat sebagai Mojang Kota Bandung yaitu menjadi perhatian masyarakat dan segala sesuatu harus menggunakan manner. Akasha dan Nabila dalam menyiapkan risiko itu mereka dengan cara menjaga diri dan memperbaiki diri.

Dari hasil penelitian ini, peneliti menyarankan: Pinilih Mojang Kota Bandung 
2014-2015Akasha dan Nabila agar memperbaiki kompetensi mojang kota Bandung yang belum ada dalam diri mereka, seperti feminin dan anggun. Dengan cara berpakaian lebih sedikit feminin meskipun tidak saat bertugas. Dan peneliti melihat belum maksimalnya kompetensi yang dimiliki oleh Akasha dan Nabila saat bertugas, peneliti menyarankan kepada paguyuban untuk memberikan tugas yang lebih untuk dapat memaksimalkan komptensi Akasha dan Nabila tidak hanya sebagai penyambut tamu.

Akasha dan Nabila tetaplah berfokus saat melakukan tugas sebagai Mojang Kota Bandung dan sebaiknya saat tidak bertugas sebagai Mojang tetap harus menunjukkan sikap bahwa Akasha dan Nabila adalah seorang Mojang, serta Akasha dan Nabila sebaiknya lebih berhati-hati dalam melakukan sesuatu, seperti penggunaan sosial media. Akasha dan Nabila harus lebih bisa menjaga media sosial mereka, lebih berhati-hati dalam memposting sesuatu karena akan berdampak pada diri mereka dan paguyuban kota Bandung.

\section{DAFTAR PUSTAKA}

Cresswel, J. W. (2009). Research design, qualitative, quantitative andmixed methods. 3rd ed. Thousand Oaks. California: Sage Publications

Eliot, T. S. \& Prufrock, J. A. (2013). Self presentation. Diakses dari http://faculty. washington.edu/jdb/452/452_chapter_07. pdf

Goffman, E. (1959). The presentation of self in everyday life. Harmondworth: Penguin

Jones E. E. (1990). Interpersonal perception. New York: W. H. Freeman

Mojang Jajaka. (2013). Apa itu mojang jajaka kota bandung. Diakses dari http:// mojangjajakabdg.blogspot.co.id/2013/08/ apa-itu-mojang-jajaka-kota-bandung.html

Morissan, M. A. (2012). Metode penelitian survei. Jakarta: Kencana

Mustafa, H. (2011). Perilaku manusia dalam perspektif psikologi sosial. Jurnal Administrasi Bisnis. Vol 7 no. 2, 47-60

Paliszkiewicz, J. \& Madra-sawicka, M. (2011). Impression management in social media. Journal Management, 203-212

Sedarmayanti. (2011). Manajemen sumber daya manusia, reformasi birokrasi dan. manajemen pegawai negeri sipil (cetakan kelima). Bandung: Refika Aditama

Sugiyono. (2010). Metodologi penelitian kuantitatif kualitatif dan $r \& d$. Bandung: Alfa Beta

Terry, C. (2013). Self-promotion effects in news media. The McMaster Journal of Communication, 8-25

Wisata Bandung. (2015). Pasanggiri mojang jajaka kota bandung 2015. Diakses dari http://www.wisatabdg.com/2015/08/ pasanggiri-mojang-jajaka-kota-bandung. html 